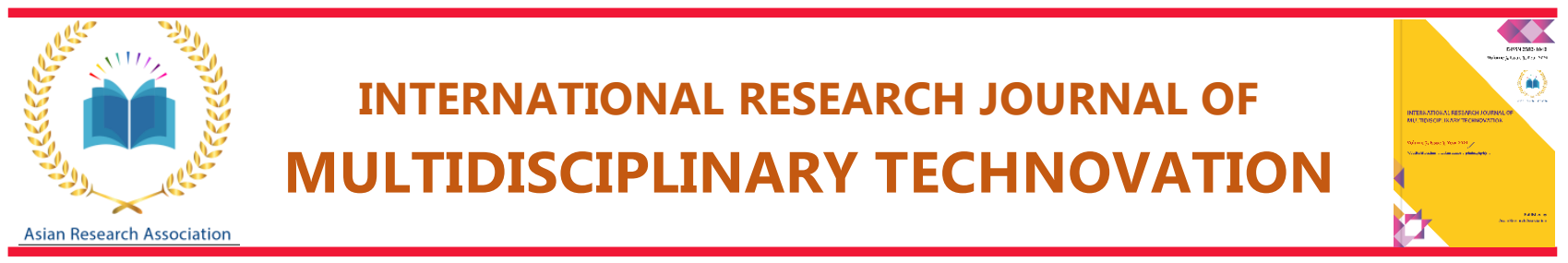

\title{
Influence of Additives on the Fatigue Life and Stiffness of Asphalt Concrete
}

\author{
Saad I. Sarsam 1,2, * \\ ${ }^{1}$ Sarsam and Associates Consult Bureau (SACB), Baghdad, Iraq. \\ ${ }^{2}$ Formerly at Department of Civil Engineering, College of Engineering, University of Baghdad, Iraq. \\ ${ }^{*}$ Corresponding authors email: saadisasarsam@coeng.uobaghdad.edu.iq \\ DOI: https://doi.org/10.54392/irjmt2162 \\ Received: 20-05-2021, Revised: 12-07-2021; Accepted: 12-08-2021, Published: 16-10-2021
}

Abstract: Implementation of additives to the asphalt binder can enhance the overall physical properties of the modified asphalt concrete. In the present assessment, an attempt has been made to use $2 \%$ of silica fumes and 4 $\%$ of fly ash class $\mathrm{F}$ for modification of asphalt binder in wet process. Asphalt concrete wearing course mixtures have been prepared and compacted by roller in the laboratory. The beam specimens of $400 \mathrm{~mm}$ length and $50 \mathrm{~mm}$ height and $63 \mathrm{~mm}$ width were extracted from the slab samples. The specimens were subjected to the four-point repeated flexural bending beam test. The flexural stiffness was calculated under three constant micro strain levels of $(250,400$, and 750$)$. The fatigue life was monitored in terms the number of load repetitions to reach the required reduction in stiffness. It was concluded that the flexural stiffness increases by (11, and 15$) \%$, (17.7, and 63.6) \%, (57.2, and 65 ) \% when $2 \%$ of silica fumes or $4 \%$ of fly ash are implemented and the specimen's practices 750 , 400, and 250 microstrain levels respectively. However, the fatigue life of asphalt concrete beam specimens increases by $(40$, and 72.8$) \%$, (115, and 220.6$) \%$, (46, and 94.6$) \%$ when $2 \%$ of silica fumes or $4 \%$ of fly ash are implemented and the specimen's practices 750,400 , and 250 microstrain levels respectively. It is recommended to use modified binder with fly ash and silica fumes in asphalt concrete to enhance the fatigue life and stiffness.

Keywords: Asphalt concrete, Flexural Stiffness, Fatigue life, Silica Fumes, Fly ash

\section{Introduction}

Adhikari and You, [1] used beam fatigue test to evaluate the fatigue life and flexural stiffness of the asphalt concrete beam specimens. A frequency level of $10 \mathrm{~Hz}, 5 \mathrm{~Hz}$, and $1 \mathrm{~Hz}$ and a constant strain levels of 400,300 , and 200 micro strains have been implemented. It was reported that fatigue life declines when the asphalt concrete beam was tested with high loading frequency and high strain level. However, the fatigue life of asphalt concrete was high at low strain level and low loading frequency. Kakade et al., [2] investigated the influence of different proportions of hydrated lime additive on the rutting behavior of bituminous mixes. The rutting behavior of lime modified, and control binders have been determined in terms of the Superpave binder rutting parameter. It was concluded that rutting behavior of asphalt concrete mixtures improved significantly after modification with lime. It was also noticed that the influence of lime addition on rutting control at hot environment was realized. Al-Mohammedawi and Mollenhauer, [3] identified the influence of active fillers such as limestone, cement, ladle slag, and silica fume on the fatigue behavior and the rheological properties of cold bitumen emulsion mastic. The investigation was accompanied by the chemical analysis for the emulsified bitumen-filler. The emulsified bitumen was mixed separately with the fillers to preparation of the mastics. Test results exhibit that the fatigue damage resistance and the rheological performance depend on the filler type and chemistry of the mixture. It was concluded that the addition of mineral fillers can significantly change the fatigue damage resistance and the rheological response of the mastic as reported by Lesueur et al., [4]. Buczy et al., [5] stated that the mineral fillers can be grouped chemically into inactive and active fillers, depending on their reactivity within the bitumen emulsion. Limestone is classified as inactive filler although it is considered as inert filler, because of its mineral composition. It is usually implemented as a regulator for the stiffness by adding it as a solid particle to the binder matrix. Underwood and Kim, [6] reported that fillers can strengthen the asphalt binder through the three main mechanisms of chemical interaction, volume filling, and particle geometry. The 
volume filling and particle geometry are considered as a possible mechanical reinforcement. Khan et al., [7] assessed the influence of different fillers on some properties of asphalt concrete mixtures. Two filler types, silica fumes and marble dust were used to investigate the impact of filler / asphalt ratio on the properties of asphalt mixtures. It was concluded that the mixtures with $50 \%$ silica fume and $50 \%$ marble dust have greater stability than all the other percentages used in a Marshall mix. It has also void content of 6.8 which is within the specification. All other air voids results are out of range. All other percentages of filler have lower stability and voids which are out of range. Mixture having $50 \%$ silica \& $50 \%$ marble dust has only $13.5 \mathrm{~mm}$ flow value which is greater than all other percentages. Ullah et al., [8] investigated two additives for partial substitution of fillers (Cement and Lime) which were used with two different types of aggregates quarries for evaluation of the best combination of both fillers and aggregates quarry to control the service life of asphalt concrete pavements. It was concluded that replacing the aggregate filler with cement and hydrated lime exhibits a positive influence on the performance of asphalt concrete. Partial Substitution of the filler has improved the rutting behavior at hot environment. At the same time, partial substitution of the filler has improved the adhesion properties as compared with that of the control mixture. The addition of different fillers such as cement, fly ash, hydrated lime, silica fume, and bag-house fines are known to increase the rutting resistance of asphalt concrete as stated by Bahia et al., [9]. Wang et al.,[10] revealed that implementation of cement with filler material in asphalt concrete mixture can improve the stripping resistance, stiffness, and strength of asphalt concrete. Cement exhibits a similar influence on that of mineral filler on the volumetric and physical properties of asphalt concrete. Sarsam, [11] concluded that the stiffness of asphalt concrete is susceptible to aging, the increase in Microstrain level leads into a remarkable decline in initial and failure stiffness's. The stiffness is susceptible to the testing temperature and asphalt content, lower testing temperature of 5 $\mathrm{C}$ exhibits higher stiffness value, while higher binder content has a negative impact on the stiffness. Sarsam and AL-Lamy, [12] revealed that the Fatigue life of asphalt concrete increases with the use of fly ash and silica fumes by ( $111 \%$ and $50 \%$ ) while the stiffness increased by (155 $\%$ and $124 \%$, respectively when it was compared with the conventional mix.

The aim of the present assessment is to implement $2 \%$ of silica fumes and $4 \%$ of fly ash class $\mathrm{F}$ for modification of asphalt binder in wet process. The influence of such additives on flexural stiffness and fatigue life will be assessed.

\section{The Materials Characterization}

Materials implemented in this work are locally available and usually used for asphalt pavement construction.

\section{The Asphalt Cement}

Asphalt cement of 40-50 penetration grad was implemented in this work. It was obtained from $\mathrm{AL}$ Nasiriya Refinery. Physical properties of asphalt binder are listed in Table 1.

\section{Fine and Coarse Aggregates}

Crushed coarse aggregates having a nominal maximum size of $19 \mathrm{~mm}$ and natural and crushed sand mixture was implemented as Fine aggregate. The aggregates were obtained from AL-Ukhaider quarry. The aggregates were washed, then air dried and sieved into different sizes. The physical properties of aggregates are demonstrated in Table 2.

\section{The Mineral Filler}

The mineral filler implemented in the present investigation is the limestone dust which was obtained from Karbala governorate. The filler passes sieve No.200 $(0.075 \mathrm{~mm})$. The physical properties of the mineral filler are presented in Table 3.

\section{The Fly Ash}

Fly ash of class $F$ was implemented as an additive, it was obtained from local market. The physical properties of the additive are listed in Table 4, while the chemical composition of Fly Ash is shown in Table 5.

\section{The Silica Fumes}

Silica fumes was prepared as fluffy powder, it was obtained from local market; Table 6 presents its chemical composition. Table 7 shows the physical properties of the Silica fumes.

\section{Selection of Aggregate Gradation}

The selected aggregates gradation in the present investigation follows SCRB, [14] limitations for wearing course pavement layer with dense gradation. It has $12.5 \mathrm{~mm}$ nominal maximum size of aggregates. Table 8 shows the implemented aggregate gradation. 
Table 1. The Physical properties of asphalt cement

\begin{tabular}{|l|l|l|l|l|}
\hline Property & Testing condition & $\begin{array}{l}\text { ASTM, [13] } \\
\text { Designation No. }\end{array}$ & Value & $\begin{array}{l}\text { SCRB, } \\
\text { Specifications }\end{array}$ \\
\hline Penetration & $100 \mathrm{gm}, 25^{\circ} \mathrm{C}, 5$ seconds & D5-06 & 42 & $40-50$ \\
\hline Softening Point & (Ring and Ball) & D36-895 & 49 & - \\
\hline Ductility & $25^{\circ} \mathrm{C}, 5 \mathrm{~cm} /$ minutes & D113-99 & $100+$ & $>100$ \\
\hline Specific Gravity & $25^{\circ} \mathrm{C}$ & D70 & 1.04 & - \\
\hline After thin film oven test properties according to ASTM D1754-97 & D5-06 & 33 & - \\
\hline Penetration & $100 \mathrm{gm}, 25^{\circ} \mathrm{C}, 5$ seconds & D113-99 & 83 & - \\
\hline Ductility of Residue & $25^{\circ} \mathrm{C}, 5 \mathrm{~cm} / \mathrm{mi}$ &
\end{tabular}

Table 2. Physical Properties of Fine and Coarse Aggregate

\begin{tabular}{|l|l|l|}
\hline Property & Value & ASTM, [13] Designation No. \\
\hline Coarse Aggregate & 2.542 & C127-01 \\
\hline Bulk specific gravity & $1.076 \%$ & $\mathrm{C} 127-01$ \\
\hline Water absorption \% & $18 \%$ & $\mathrm{C} 131-03$ \\
\hline Wear \% (lose Angeles's abrasion) & \multicolumn{2}{|l|}{} \\
\hline Fine Aggregate & 2.558 & $\mathrm{C} 128-01$ \\
\hline Bulk specific gravity & $1.83 \%$ & $\mathrm{C} 128-01$ \\
\hline Water absorption \% &
\end{tabular}

Table 3. The Physical Properties of limestone dust (Mineral Filler)

\begin{tabular}{|l|l|}
\hline Bulk specific gravity & \% Passing Sieve $0.075 \mathrm{~mm}$ \\
\hline 2.617 & 94 \\
\hline
\end{tabular}

Table 4. The Physical Properties of Fly Ash

\begin{tabular}{|l|l|l|l|}
\hline Sieve size $\mathbf{( m m})$ & \% passing & Specific gravity & Specific surface area $\left(\mathbf{m}^{2} / \mathbf{k g}\right)$ \\
\hline 0.075 & 98 & 2.645 & 650 \\
\hline
\end{tabular}

Table 5. The Chemical Composition of Fly Ash

\begin{tabular}{|l|l|l|}
\hline Chemical composition & Percent & ASTM C-618, [13] Requirement (\%) \\
\hline $\mathrm{SiO}_{2}$ & 61.95 & $\ldots \ldots \ldots$ \\
\hline $\mathrm{Fe}_{2} \mathrm{O}_{3}$ & 2.67 & $\ldots \ldots \ldots \ldots$ \\
\hline $\mathrm{Al}_{2} \mathrm{O}_{3}$ & 28.82 & $\ldots \ldots \ldots \ldots$ \\
\hline $\mathrm{CaO}$ & 0.88 & $\ldots \ldots \ldots \ldots$ \\
\hline $\mathrm{MgO}$ & 0.34 & $5.0 \max$ \\
\hline $\mathrm{Na}_{2} \mathrm{O}$ & 0.26 & $1.5 \max$ \\
\hline Loss on ignition & 0.86 & $6.0 \max$ \\
\hline
\end{tabular}


Table 6. The Chemical Components of Silica Fumes

\begin{tabular}{|l|l|}
\hline Chemical Composition & Percent \\
\hline $\mathrm{SiO} 2$ & 99.1 \\
\hline $\mathrm{Fe} 2 \mathrm{O} 3$ & 35.0 P.P.M \\
\hline $\mathrm{Al} 2 \mathrm{O} 3$ & $<0.035$ \\
\hline $\mathrm{TiO} 2$ & $<0.006$ \\
\hline $\mathrm{CaO} 2$ & 0.03 \\
\hline $\mathrm{MgO}$ & 52.0 P.P.M \\
\hline $\mathrm{SO} 3$ & $<0.07$ \\
\hline Loss on ignition & 0.7 \\
\hline
\end{tabular}

Table 7. The Physical Properties of Silica Fumes

\begin{tabular}{|l|l|l|l|}
\hline Sieve size $(\mathrm{mm})$ & PH value & Density $\left(\mathrm{kg} / \mathrm{m}^{3}\right)$ & Specific surface area $\left(\mathrm{m}^{2} / \mathrm{kg}\right)$ \\
\hline $\begin{array}{l}100 \% \text { Passing sieve of } 0.075 \\
\mathrm{~mm}\end{array}$ & 4.5 & 2.6455 & 200000 \\
\hline
\end{tabular}

Table 8. The Combined Gradation Implemented for Wearing Course as per SCRB, 2003[14]

\begin{tabular}{|l|l|l|l|l|l|l|l|}
\hline Sieve size $(\mathrm{mm})$ & 19 & 12.5 & 9.5 & 4.75 & 2.36 & 0.3 & 0.75 \\
\hline Implemented gradation & 100 & 95 & 83 & 59 & 43 & 13 & 7 \\
\hline SCRB, [14] limitations & 100 & $90-100$ & $76-90$ & $44-74$ & $28-58$ & $5-12$ & $4-10$ \\
\hline
\end{tabular}

\section{Preparation of Modified Asphalt Cement}

Modified asphalt binder is prepared by implementing the wet process technique. In this process, asphalt cement was heated to $150^{\circ} \mathrm{C}$. The fly ash or silica fumes were added in powder form using various percentages of each additive. The mixture was blended in a mixer at a blending speed of $1300 \mathrm{rpm}$ and the mixing temperatures of $160^{\circ} \mathrm{C}$ was maintained for 20 minutes to enable the possible chemical and physical bonding of the components. The optimum percentages of fly ash and Silica fumes are (4 and 2) \% by weight of binder respectively. Details of the mixing procedure and selection of the optimum percentages could be found in Sarsam and Al-Lamy, [12].

\section{Preparation of Asphalt Concrete Mixture and Specimens}

The fine and coarse aggregates were combined with the mineral filler to meet the specified gradation for wearing course. The combined aggregates were then heated to $160{ }^{\circ} \mathrm{C}$. The asphalt cement or the modified asphalt binder was heated to $150 \stackrel{\circ}{\circ}$ so that it can produce a kinematic viscosity of

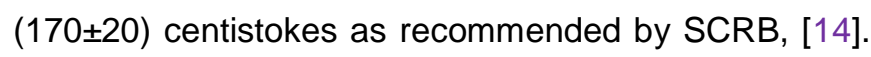
Then, the asphalt cement binder was added to the heated combined aggregates mixture to achieve the desired amount and mixed thoroughly for two minutes until all aggregate particles were coated with the binder. The mixture had practiced a short-term ageing process for 4 hours at temperature of $135^{\circ} \mathrm{C}$ according to AASHTO R-30, [15]. The optimum binder content of $4.9 \%$ was implemented. The optimum binder percentage was determined based on Marshall trial mixes using various asphalt percentages. Details of obtaining the optimum binder content could be found in Sarsam and Al-Lamy, [16]. The short-term aged mixtures were casted in a slab mold of $(40 \times 30 \times 6) \mathrm{cm}$ and subjected to roller compaction to the target bulk density for each binder type according to EN12697-33, [17]. The applied static load was $5 \mathrm{kN}$ while the number of load passes depended on the asphalt type in mixture and was determined based on trial-and-error process. Details of the compaction process could be referred to Sarsam, [11]. The compaction temperature was maintained to $150^{\circ} \mathrm{C}$. Slab samples were left to cool overnight. Beam specimens of $63 \pm 2 \mathrm{~mm}$ width and $50 \pm 2 \mathrm{~mm}$ high, and $400 \mathrm{~mm}$ length were obtained from the compacted slab sample using the Diamond-saw. 
The total number of beam specimens obtained was twelve, while the number of casted slabs was three.

\section{Repeated Flexural Bending Beam Test}

The four-point repeated flexural bending beam test was implemented according to AASHTO T321, [18] to identify the impact of additives on the fatigue life and flexural stiffness of asphalt concrete beam specimens at intermediate pavement operating temperature of 20 ${ }^{\circ} \mathrm{C}$ and under constant strain level. During the flexural fatigue test, the asphalt concrete beam is subjected to repeated four-point loading. The load frequency is usually set $5 \mathrm{~Hz}$, and the vertical deformation caused by the loading is detected at the center of the beam. A repeated haversine (sinusoidal) load is applied to the two inner clamps on the asphalt concrete beam specimen while the outer clamps are providing a reaction load. This setup of the beam specimen produces a constant bending moment over the central portion of the beam (between the two inside clamps). The asphalt concrete beam specimens were subjected to a repeated load at a constant strain level. Three different Microstrain levels of 250, 400, and 750 were tried to simulate various modes of loading in the field.

\section{Discussion of Test Results}

\section{Influence of Additives on Flexural Stiffness of Asphalt Concrete}

As demonstrated in Figure 1, implementation of additives exhibits positive influence on the flexural stiffness regardless of the microstrain level implemented. However, as the strain level increases, the flexural stiffness declines regardless of the additives implemented. The flexural stiffness increases by (11, and 15$) \%$, (17.7, and 63.6$) \%$, (57.2, and 65$) \%$ when $2 \%$ of silica fumes or $4 \%$ of fly ash are implemented and the specimen's practices 750,400 , and 250 microstrain levels respectively. On the other hand, when the strain level decline from 250 to 400 and 750 , the flexural stiffness declines by (60.3, and 71.4), (70.3, and 79.7), (60.7, and 80) for control, modified mixture with $2 \%$ silica fumes and modified mixture with $4 \%$ fly ash respectively. Similar findings were reported by Bahia et al., [9] and Sarsam, [11].

\section{Influence of Additives on the Fatigue Life of Asphalt Concrete}

Figure 2 exhibit the impact of additives on fatigue life of asphalt concrete beam specimens. It can be noted that implementation of additives exhibits positive influence on the fatigue life of asphalt concrete regardless of the microstrain level implemented. However, as the strain level increases, the fatigue life declines regardless of the additives implemented. The fatigue life increases by (40, and 72.8$) \%$, (115, and $220.6) \%$, (46, and 94.6$) \%$ when $2 \%$ of silica fumes or $4 \%$ of fly ash are implemented and the specimen's practices 750, 400, and 250 microstrain levels respectively. On the other hand, when the level of strain decline from 250 to 400 and 750 , the fatigue life declines by (83.2, and 96.5), (75.2, and 96.6), (72.3, and 97 ) for control, modified mixture with $2 \%$ silica fumes and modified mixture with $4 \%$ fly ash respectively. Such behavior exhibit an agreement with the work reported by Sarsam and AL-Lamy, [12].

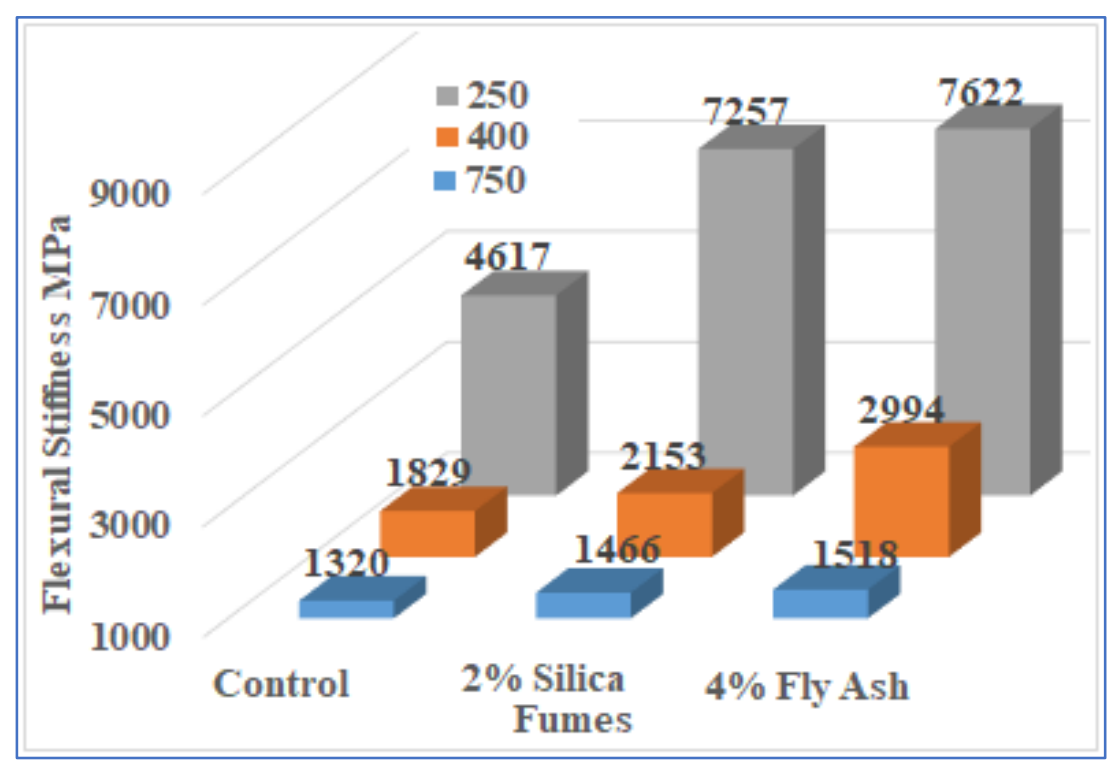

Figure 1. Influence of Additives on Flexural Stiffness 


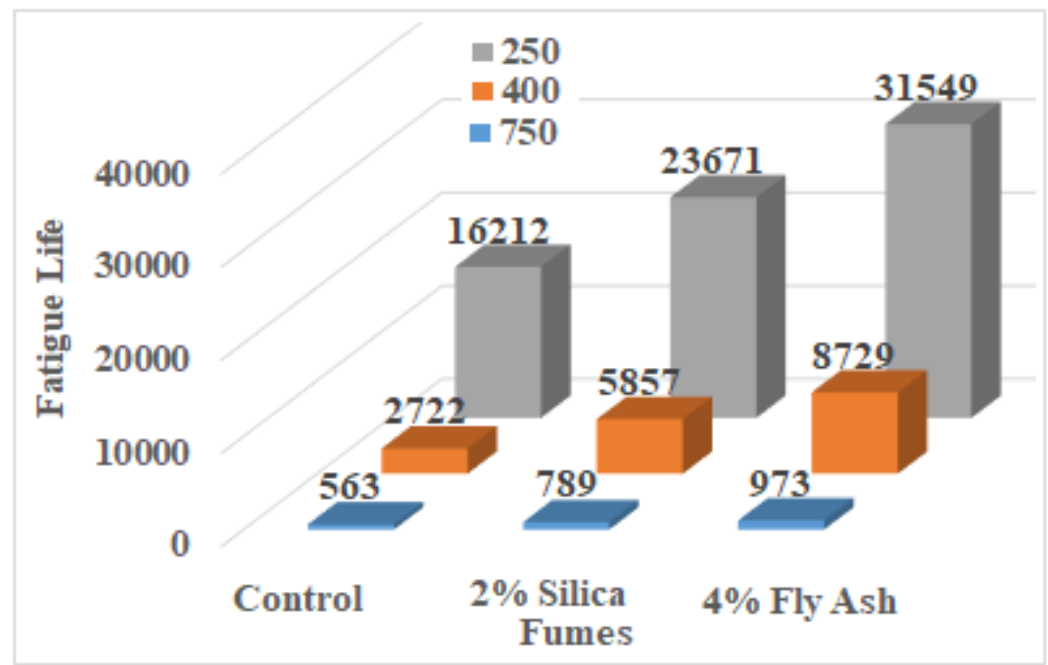

Figure 2. Influence of Additives on Fatigue Life

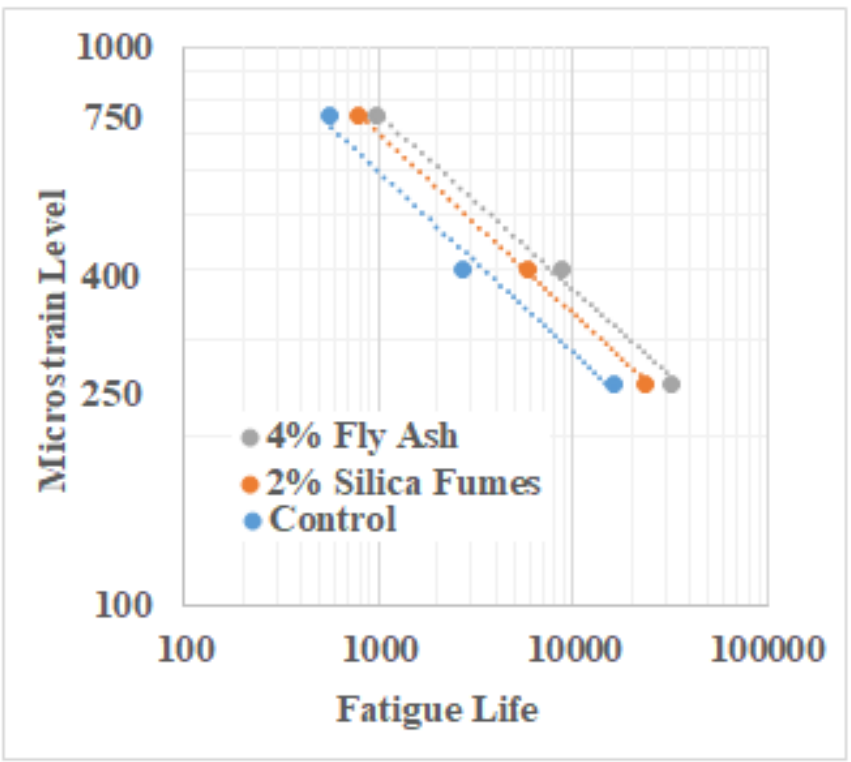

Figure 3. Influence of Additives on Rate of Deterioration in fatigue life of Asphalt Concrete

Table 9. Deterioration Parameters of Asphalt Concrete

\begin{tabular}{|l|l|l|l|}
\hline Mixture Type & Slope & Mathematical Model & $\mathbf{R}^{\mathbf{2}}$ \\
\hline Control & -0.326 & $\mathrm{Y}=5663.5 \mathrm{X}^{-0.326}$ & 0.985 \\
\hline $2 \%$ Silica Fumes & -0.322 & $\mathrm{Y}=6473.7 \mathrm{X}^{-0.322}$ & 0.999 \\
\hline $4 \%$ Fly Ash & -0.313 & $\mathrm{Y}=6546.4 \mathrm{X}^{-0.313}$ & 0.995 \\
\hline
\end{tabular}

Influence of Additives on Rate of Deterioration of Asphalt Concrete

Figure 3 demonstrate the influence of additives on the rate of deterioration in the fatigue life of asphalt concrete beam specimens, it can be noticed that the fatigue life increases after the implementation of additives. It can be noted that the fatigue life increased after implementing silica fumes and fly ash as additives respectively. Moreover, implication of additives exhibits 
a gentle deterioration in fatigue life of asphalt concrete beam specimens as compared with control mixture. Table 9 shows that the slope declines from 0.326 for control mixture to 0.322 and 0.313 for silica fumes and fly ash treated mixtures respectively.

\section{Conclusion}

Based on the materials implemented and the limitations of testing program, the following conclusions may be addressed.

1. The flexural stiffness increases by (11, and 15) $\%$, (17.7, and 63.6) \%, (57.2, and 65) \% when $2 \%$ of silica fumes or $4 \%$ of fly ash are implemented and the specimen's practices 750, 400, and 250 microstrain levels respectively.

2. The fatigue life of asphalt concrete increases by $(40$, and 72.8$) \%$, (115, and 220.6$) \%$, (46, and 94.6 ) $\%$ when $2 \%$ of silica fumes or $4 \%$ of fly ash are implemented and the specimen's practices 750, 400, and 250 microstrain levels respectively.

3. Implication of additives exhibits a gentle deterioration in the fatigue life of asphalt concrete as compared with control mixture. The slope declines from 0.326 for control mixture to 0.313 and 0.322 for fly ash and silica fumes treated mixtures respectively.

4. It is recommended to use modified binder with fly ash and silica fumes in asphalt concrete to enhance the fatigue life and stiffness.

\section{References}

[1] S. Adhikari, Z. You, Fatigue Evaluation of Asphalt Pavement using Beam Fatigue Apparatus, The Technology Interface Journal/Spring, 10 (2010).

[2] V.B. Kakade, M.A. Reddy, K.S. Reddy, Rutting performance of hydrated lime modified bituminous mixes, Construction and Building Materials, 186 (2018) 1-10. [DOI]

[3] A. Al-Mohammedawi, K. Mollenhauer, A Study on the Influence of the Chemical Nature of Fillers on Rheological and Fatigue Behavior of Bitumen Emulsion Mastic, Materials, 13 (2020) 4627. [DOl]

[4] D. Lesueur, A. Teixeira, M.M. Lázaro, D. Andaluz, A. Ruiz, A simple test method in order to assess the effect of mineral fillers on bitumen ageing, Construction and Building Materials, 117 (2016) 182-189. [DOI]

[5] P. Buczy' nski, M. Iwa' nski, Inactive Mineral Filler as a Stiffness Modulus Regulator in
Foamed Bitumen-Modified Recycled Base Layers, IOP Conference Series: Materials Science and Engineering, 245 (2017) 032042. [DOl]

[6] B.S. Underwood, Y.R. Kim, Experimental investigation into the multiscale behavior of asphalt concrete, International Journal of Pavement Engineering, 12, (2011) 357-370. [DOI]

[7] A. A. Khan, N. Ullah, A. Ahmad, S. Ali, Evaluation of mechanical properties of hot mix asphalt by replacing the combination of marble dust and silica fume as a filler, Global Scientific Journals, 8 (2020) 681-690.

[8] R. Ullah, I. Hafeez, S. Zaidi, Jamal, S. Safeer Haider, Study the Effect of Substitution Filler on performance of Asphalt Mixture, Civil Engineering Journal, 6 (2020). [DOl]

[9] H. Bahia, D. I. Hanson, M. Zeng, H. Zhai, M. Khatri, R. Anderson, (2001) Characterization of modified asphalt binders in Superpave mix design, National Technical Reports Library.

[10] J. Wang, M. Guo, Y. Tan, Study on application of cement substituting mineral fillers in asphalt mixture, International Journal of Transportation Science and Technology, 7 (2018) 189-198. [DOl]

[11] S.I. Sarsam, Influence of Aging, Temperature and Moisture Damage on the Stiffness of Asphalt Concrete through the Fatigue Process, International Journal of Scientific Research in Knowledge, 4 (2016) 077-084, [DOI]

[12] S.I. Sarsam, A.K. AL-Lamy, Fatigue life assessment of Modified Asphalt Concrete, International Journal of Scientific Research in Knowledge, 3 (2015) 030-041. [DOl]

[13] ASTM, Road and Paving Materials, Annual Book of ASTM Standards, Volume 04.03, American Society for Testing and Materials, (2015) West Conshohocken, USA.

[14] SCRB, State Commission of Roads and Bridges, Standard Specification for Roads \& Bridges, (2003) Ministry of Housing \& Construction, Iraq.

[15] AASHTO, R-30, Standard Practice for Mixture Conditioning of Hot Mix Asphalt, AASHTO Provisional Standards. (2002) Washington, D.C.

[16] S.I. Sarsam, A.K. AL-Lamy, Fatigue Behavior of Modified Asphalt Concrete Pavement, Journal of Engineering, 22 (2016) 1-10.

[17] EN 12697 - 33. Bituminous Mixtures - Test Methods for Hot Mix Asphalt - part 33: Specimen prepared by Roller Compactor, (2007) European Committee for Standardization.

[18] AASHTO T-321, (2010) Standard Method of 
Test for Determining the Fatigue Life of Compacted Asphalt Mixtures Subjected to Repeated Flexural Bending, AASHTO Provisional Standards, Washington, D.C.

\section{Funding}

No funding was received for conducting this study.

\section{Conflict of interest}

The Author has no conflicts of interest to declare that they are relevant to the content of this article.

Does this article screened for similarity?

Yes

\section{About the License}

(c) The author 2021. The text of this article is open access and licensed under a Creative Commons Attribution 4.0 International License 